\title{
Calcitonin levels are similar in goitrous euthyroid patients with or without thyroid antibodies, as well as in hypothyroid patients
}

\author{
Helen Pantazi and Peter D Papapetrou \\ Department of Medicine, Second Division of Endocrinology, 'Alexandra' Hospital, Athens, Greece \\ (Correspondence should be addressed to P D Papapetrou, Alexandra' Hospital, Vas. Sofias and K. Lourou Street, 11528, Athens, Greece)
}

\begin{abstract}
Objective: Some authors, after studying retrospectively immunostained sections of thyroid specimens, found C-cell hyperplasia ( $\mathrm{CCH})$ unrelated to medullary thyroid carcinoma to be frequent in thyroid glands affected by chronic lymphocytic thyroiditis (CLT); others failed to observe this association. The purpose of the present study was to further investigate prospectively the existence of the proposed relationship between CLT and CCH by measuring circulating calcitonin (CT) levels.

Design: Basal serum CT was measured in 174 euthyroid goitrous women with negative thyroid autoantibodies (TA-Neg) and 124 age-matched goitrous euthyroid women with positive antibodies (TA-Pos). A calcium-infusion test was performed in 27 TA-Neg and 31 TA-Pos age-matched euthyroid goitrous women. Basal CT was also determined in 51 hypothyroid women and 40 control normal healthy women.

Methods: Serum CT was measured using a specific and sensitive two-site immunoassay which detects mainly the CT-32 monomer. Thyroid autoantibodies (anti-thyroid peroxidase and anti-thyroglobulin) were measured in serum by quantitative RIAs.

Results: Basal serum CT was found to be similar in TA-Neg and TA-Pos euthyroid as well as hypothyroid and normal control groups. A test of independence performed on the frequency distribution of the patients among sequential classes of serum CT showed that basal CT levels are independent of the presence of thyroid autoantibodies or hypothyroidism. Calcium-stimulated CT as well as the increase in CT were similar in TA-Neg and TA-Pos euthyroid goitrous women. There was no correlation between thyrotropin and CT in the hypothyroid group.

Conclusion: Positive thyroid antibodies in goitrous patients do not predispose to hypercalcitoninemia. Elevated CT found in a patient with goitre and positive thyroid antibodies should not be ascribed to the underlying thyroiditis; this patient should be investigated for some other cause of the high CT.
\end{abstract}

European Journal of Endocrinology 138 530-535

\section{Introduction}

Serum calcitonin (CT), the hormone secreted by the $\mathrm{C}$ cells of the thyroid, is a useful marker for the diagnosis and assessment of the treatment of medullary thyroid carcinoma (MTC). However, CT is not an absolutely specific marker of this tumor, since some other tumors may secrete CT occasionally (1). Elevated plasma CT is due usually to underlying MTC or its precursor malignant $\mathrm{C}$-cell hyperplasia $(\mathrm{CCH})$. $\mathrm{CCH}$ unrelated to MTC has been found by some authors in such conditions as old age, hyperparathyroidism, and in the vicinity of follicullar thyroid tumors $(2-7)$. Some authors have reported $\mathrm{CCH}$, defined by morphological immunohistochemical methods, to be present in a significant proportion of thyroid glands affected by chronic lymphocytic thyroiditis (CLT) (8-12), while others have not found such an association between CLT and $\mathrm{CCH}$ (13-16). In a minority of patients with CLT and $\mathrm{CCH}$, elevated serum $\mathrm{CT}$ has been reported (9-11). Thus, the proposed association between CLT and CCH remains controversial. The determination of serum CT in all patients with thyroid nodules as a screening procedure for the early diagnosis of MTC has been proposed recently (17-19). However, the limited specificity of mildly elevated serum CT may create diagnostic problems in many patients if this procedure is employed (20), and it would be very useful to clarify various conditions unrelated to MTC in which high CT may occur. In this prospective study therefore we measured serum $\mathrm{CT}$ in goitrous patients with either negative or positive thyroid antibodies (TA-Neg or TA-Pos) in order to investigate if CLT is a cause of hypercalcitoninemia and $\mathrm{CCH}$. We found similar and normal serum CT levels in TA-Neg and TA-Pos patients. 


\section{Materials and methods}

All patients in this study had an intact thyroid, i.e. they had not previously been treated by either thyroidectomy or with radioiodine. In order to avoid variation in CT levels due to gender, only female subjects were studied. These were euthyroid women, of whom $90 \%$ had diffuse goitre on palpation and $10 \%$ had nodular goitres diagnosed by palpation or ultrasound. Single or otherwise suspicious nodules were routinely examined by fine needle biopsy, and patients with malignant nodules were excluded. A total of 174 patients aged $45.6 \pm 14.0$ (mean \pm S.D.) were TA-Neg, and 124 aged $45.8 \pm 13.8$ were TA-Pos, with antibody concentrations diagnostic of CLT $(>500 \mathrm{U} / \mathrm{ml})$. The patients in the two groups were carefully age-matched (Table 1). About $46 \%$ of the patients in each group were on thyrotropin (TSH)-suppressive doses of thyroxine.

A subgroup of 27 TA-Neg patients aged $42.5 \pm 9.3$ and 31 TA-Pos patients aged $42.5 \pm 10$ received a $10 \mathrm{~min}$ calcium gluconate infusion $(2.7 \mathrm{mg} \mathrm{Ca} / \mathrm{kg})$, and $\mathrm{CT}$ and total $\mathrm{Ca}$ were measured just before the start and at the end of the infusion. The change in CT $(\Delta \mathrm{CT})$ was calculated by subtracting the basal from the Ca-stimulated value for each individual.

A group of 51 hypothyroid women aged $50.7 \pm 13.9$ were studied separately; $21(41 \%)$ of them were on replacement therapy with thyroxine (with TSH $<3.5 \mathrm{mU} / \mathrm{l})$ and the rest had high TSH (24.7 \pm $23.6 \mathrm{mU} / \mathrm{l}$; mean \pm s.D.). A group of 40 control normal healthy women aged $37.8 \pm 8.8$ was also studied. The assays were performed on fasting blood specimens obtained between 0830 and $1000 \mathrm{~h}$. Informed consent was obtained from all the women who participated in the study, which was approved by the scientific committee of the hospital.

Serum human CT was determined using a two-site chemiluminescence immunoassay (Nichols Institute Diagnostics, San Juan Capistrano, CA, USA). This assay utilizes two monoclonal antibodies against human (h) CT (one of them directed against hCT(1123 ) and the second against $\mathrm{hCT}(21-32))$, synthetic

Table 1 Age matching between the patients of the two groups.

\begin{tabular}{lcr}
\hline & \multicolumn{2}{c}{$\begin{array}{c}\text { Patients per decade } \\
\text { in each group (\%) }\end{array}$} \\
\cline { 2 - 3 } $\begin{array}{l}\text { Age } \\
\text { (years) }\end{array}$ & TA-Pos & TA-Neg \\
\hline $11-20$ & 2.7 & 3.0 \\
$21-30$ & 9.7 & 13.7 \\
$31-40$ & 23.9 & 18.5 \\
$41-50$ & 28.3 & 28.6 \\
$51-60$ & 19.5 & 20.8 \\
$61-70$ & 12.3 & 11.3 \\
$71-80$ & 3.6 & 4.1 \\
\hline
\end{tabular}

hCT(1-32) as standard, and detects mainly the CT(132) monomer excluding fragments and polymers of the CT molecule. The sensitivity of the assay (defined as mean +2 s.D. relative light units of the zero standard) was $0.3 \mathrm{pg} / \mathrm{ml}(0.09 \mathrm{pmol} / \mathrm{l})$ and the functional sensitivity (coefficient of variation $(\mathrm{CV})<15 \%$ ) was $1.6 \mathrm{pg} / \mathrm{ml}$ $(0.47 \mathrm{pmol} / \mathrm{l})$. Undetectable CT $(<0.09 \mathrm{pmol} / \mathrm{l})$ was assigned the value of $0.03 \mathrm{pmol} / \mathrm{l}$ for the purpose of calculations. The within-assay $\mathrm{CV}$ was $3.3 \%$ and the between-assay CV $9.5 \%$ at the $9 \mathrm{pg} / \mathrm{ml}(2.63 \mathrm{pmol} / \mathrm{l})$ level. This assay was found to be equivalent to another commercial two-site IRMA for hCT (CIS, Gif-sur-Yvette, France) (21) previously also used in our laboratory.

Anti-thyroid peroxidase (anti-TPO) and antithyroglobulin (anti-Tg) thyroid autoantibodies (TAs) were measured in serum using RIAs (BRAMS-Henning diagnostica, Berlin, Germany). The serum of $95 \%$ of healthy normal persons reacts in both these RIAs to a level of less than $100 \mathrm{U} / \mathrm{ml}$, and values above this cutoff point are considered to be TA-Pos. However, only patients with TA values five times or more above the cutoff point $(>500 \mathrm{U} / \mathrm{ml})$ in at least one of the two assays were characterized as TA-Pos, and patients with TA values less than $100 \mathrm{U} / \mathrm{ml}$ in both assays were characterized as TA-Neg, and they were included in the study. Patients with TA values of $100-500 \mathrm{U} / \mathrm{ml}$ were excluded from the study.

TSH was measured by a third-generation chemiluminescence two-site immunoassay (Nichols Institute Diagnostics) with a sensitivity of $0.01 \mathrm{mU} / \mathrm{l}$, a functional sensitivity of $0.04 \mathrm{mU} / \mathrm{l}$, within-assay $\mathrm{CVs}$ of 4.3 and $4.1 \%$, between-assay CVs of 9.1 and $8.7 \%$ at the 0.5 and $1.2 \mathrm{mU} / \mathrm{l}$ levels respectively, and euthyroid range $0.4-3.6 \mathrm{mU} / \mathrm{l}$.

\section{Statistical analysis}

The distribution of $\mathrm{CT}$ values was skewed to the right and therefore, for each group, the geometric mean, 95\% confidence interval, range and median are given; the CT levels between two groups were compared using the Mann-Whitney test. In order to evaluate whether high CT values (basal or Ca-stimulated $\Delta \mathrm{CT}$ ) are associated with positive TA an independence test was performed as follows. The two criteria (TA-Pos or TA-Neg) were divided into several arbitrary classes of sequentially ascending CT values, and a frequency distribution of the patients was carried out among the classes. The $\chi^{2}$ test was used for the assessment of independence. The Spearman rank correlation test was used for comparisons between CT and TA or TSH values. The normally distributed serum Ca levels were compared by the $t$-test.

\section{Results}

Of the 174 euthyroid TA-Neg patients, 112 (64.4\%) had undetectable CT, and, of the 124 TA-Pos patients, 77 
Table 2 CT levels in goitrous euthyroid patients with either positive or negative thyroid antibodies (TA).

\begin{tabular}{llll}
\hline & \multicolumn{1}{c}{ TA-Pos } & \multicolumn{1}{c}{ TA-Neg } & \multicolumn{1}{c}{ Control } \\
\hline With detectable CT & $n=47$ & $n=62$ & $n=12$ \\
Geometric mean & 0.52 & 0.53 & 0.61 \\
$95 \% \mathrm{Cl}$ & $0.39-0.67$ & $0.44-0.64$ & $0.37-1.02$ \\
Range (median) & $0.09-2.90(0.52)$ & $0.15-2.52(0.50)$ & $0.12-2.84(0.61)$ \\
All patients & $n=124$ & $n=174$ & $n=40$ \\
Geometric mean & 0.09 & 0.08 & 0.07 \\
95\% Cl & $0.07-0.11$ & $0.07-0.10$ & $0.05-0.11$ \\
Range (median) & $0.03-2.90(0.03)$ & $0.03-2.52(0.03)$ & $0.03-2.84(0.03)$ \\
\hline
\end{tabular}

CT levels are expressed in pmol/l. Non-detectable CT was given the value of $0.03 \mathrm{pmol}$.

Controls are normal healthy women.

$\mathrm{Cl}$, confidence interval.

(62.1\%) had undetectable CT. The distribution of CT values was skewed to the right for both groups. The geometric mean and 95\% confidence interval (cases with undetectable CT included) was $0.08 \mathrm{pmol} / \mathrm{l}(0.07-$ $0.10)$ for the TA-Neg and $0.09 \mathrm{pmol} / \mathrm{l}(0.07-0.11)$ for the TA-Pos group (Table 2). A comparison of the CT values of the two groups showed no significant difference (Mann-Whitney test, $P=0.71$ ). The result was similar if only the cases with detectable CT were considered $(P=0.92)$ (Table 2). The individual CT values of the TA-Pos and TA-Neg euthyroid groups (criteria) were classified into five $0.6 \mathrm{pmol} / \mathrm{l}$-interval classes, and a frequency distribution of the patients among the classes was tabulated. A test of independence showed that CT levels and positive TA are independent, whether all the patients $\left(\chi^{2}=2.32, P=0.67\right)$ or only the patients with detectable CT were considered $\left(\chi^{2}=2.18, P=0.70\right)$ (Table 3$)$. The TA results of the euthyroid TA-Pos patients were the following: antiTPO: $\quad$ mean $=3028 \mathrm{U} / \mathrm{ml}, \quad$ S.D. $=4267$, range $=0-$ 30452, median $=1832$; anti-Tg: mean $=806 \mathrm{U} / \mathrm{ml}$, S.D. $=1717$, range $=0-9508$, median $=229$. A frequency distribution of the TA-Pos patients among classes according to TA concentration is shown in
Table 4. No correlation was found between CT and either anti-TPO or anti-Tg values.

The responses of CT to the Ca-stimulation test are shown in Table 5. A comparison (Mann-Whitney test) of basal CT $(P=1.0)$, Ca-stimulated CT $(P=0.52)$, and $\Delta \mathrm{CT}(P=0.41)$ in the TA-Neg and TA-Pos groups showed that there was no significant difference. For the TA-Neg group, basal serum Ca (mean \pm s.D.) was $2.23 \pm 0.11 \mathrm{mmol} / \mathrm{l}$, post-infusion $\mathrm{Ca} 2.62 \pm$ $0.14 \mathrm{mmol} / \mathrm{l}$ and $\Delta \mathrm{Ca} 0.40 \pm 0.09 \mathrm{mmol} / \mathrm{l}$; for the TAPos group the respective serum $\mathrm{Ca}$ values were $2.23 \pm 0.10,2.62 \pm 0.09$ and $0.40 \pm 0.08$. There was no statistically significant difference in the corresponding mean serum $\mathrm{Ca}$ values between the two groups (t-test). A significant linear positive Spearman rank correlation was found between basal CT and $\Delta \mathrm{CT}$ in the TA-Neg $\left(R_{\mathrm{s}}=0.67, P=0.0001\right)$ and TA-Pos $\left(R_{\mathrm{s}}=0.43, \mathrm{P}=0.02\right)$ groups, while no correlation was found between $\Delta \mathrm{CT}$ and $\Delta \mathrm{Ca}$. The $\Delta \mathrm{CT}$ values for the TA-Neg and TA-Pos euthyroid patients (criteria) were divided into the following five classes (CT pmol/l intervals): 0-3.0, 3.1-6.0, 6.1-14.6, 14.7-29.3 and $>29.3$. The frequency distributions of the patients of both groups among these classes were tabulated (not

Table 3 Frequency distribution of patients among various classes of CT concentrations.

\begin{tabular}{|c|c|c|c|c|c|}
\hline \multirow[b]{3}{*}{ Class* } & \multicolumn{3}{|c|}{ All patients (\%) } & \multirow{2}{*}{\multicolumn{2}{|c|}{$\frac{\text { Patients with detectable CT (\%) }}{\text { Euthyroid }}$}} \\
\hline & \multicolumn{2}{|c|}{ Euthyroid } & \multirow[b]{2}{*}{ Hypothyroid } & & \\
\hline & TA-Pos & TA-Neg & & TA-Pos & TA-Neg \\
\hline $0-0.60$ & 83.87 & 85.63 & 88.24 & 57.45 & 59.68 \\
\hline $0.61-0.12$ & 8.87 & 7.47 & 5.88 & 23.40 & 20.97 \\
\hline $0.13-0.18$ & 4.03 & 5.17 & 3.92 & 10.64 & 14.52 \\
\hline $0.19-2.40$ & 0.81 & 1.15 & 1.96 & 2.13 & 3.23 \\
\hline $2.41-3.00$ & 2.42 & 0.57 & 0 & 6.38 & 1.61 \\
\hline$>3.00$ & 0 & 0 & 0 & 0 & 0 \\
\hline
\end{tabular}

* Serum CT (pmol/l)

The frequencies used for the computation of $\chi^{2}$ are not shown; they were transformed to percentages for easy comparison. 
Table 4 Frequency distribution of the TA-Pos patients according to TA concentration.

\begin{tabular}{lccc}
\hline $\begin{array}{l}\text { Anti-TPO } \\
(\mathrm{U} / \mathrm{ml})\end{array}$ & Patients (\%) & $\begin{array}{c}\text { Anti-Tg } \\
(\mathrm{U} / \mathrm{ml})\end{array}$ & Patients (\%) \\
\hline Neg. & 13.2 & Neg. & 27.9 \\
$<500$ & 8.8 & $<500$ & 32.4 \\
$501-1000$ & 11.8 & $501-1000$ & 22.0 \\
$1001-2000$ & 16.2 & $1001-2000$ & 10.3 \\
$2001-4000$ & 25.0 & $>2000$ & 7.4 \\
$4001-6000$ & 11.8 & & \\
$>6000$ & 13.2 & & \\
\hline
\end{tabular}

The TA-Pos group includes patients with TA concentration to $>500 \mathrm{U} / \mathrm{ml}$ for at least one of the two TAs.

Neg. values are $<100 \mathrm{U} / \mathrm{ml}$.

shown). A test of independence showed that the magnitude of $\triangle \mathrm{CT}$ is independent of the presence of positive TAs $\left(\chi^{2}=3.68, P=0.45\right)$.

The hypothyroid patients had basal serum CT (geometric mean $0.09 \mathrm{pmol} / \mathrm{l}, 95 \%$ confidence interval 0.04-0.20) that was the same as the mean CT of the euthyroid TA-Pos patients (Mann-Whitney test, $P=0.52)$. The individual CT values of the hypothyroid and euthyroid TA-Pos patients (criteria) were divided into $0.6 \mathrm{pmol} / \mathrm{l}$-interval classes (Table 3 ). The frequency distributions of the patients in the two groups among the classes were evaluated by an independence test, which showed that CT levels are independent of hypothyroidism $\left(\chi^{2}=2.14, P=0.71\right)$. CT and TSH values in the hypothyroid group did not correlate in any way.

Basal CT levels in the TA-Neg, TA-Pos and hypothyroid groups were statistically no different from those of the normal control group (Table 2).

\section{Discussion}

Two types of $\mathrm{CCH}$ of the thyroid have been recognized recently $(12,22)$. The first neoplastic type, usually of genetic origin, is considered to be a precursor of MTC, often as a part of the syndrome of multiple endocrine neoplasia type 2 (MEN 2). The second benign type of $\mathrm{CCH}$ is thought to be physiological or reactive and has been found in patients with hyperparathyroidism, in the thyroid tissue surrounding follicular carcinomas and in the thyroid glands of elderly people (2-7). Some authors have observed that $\mathrm{CCH}$ is frequently associated with CLT (8-12), while others failed to find this association (13-16). The method used to define CCH in these studies was counting of immunostained $C$ cells in thyroid gland sections and finding more than 50 per low-power magnification microscopic field. In a small proportion of patients $(7-20 \%)$ harboring both CLT and $\mathrm{CCH}(10-12)$ and in some sporadic cases (9), high serum CT was found.

In our present prospective study, serum CT was determined by a sensitive and specific assay in euthyroid patients, the majority of whom had diffuse goitre. The patients were divided into two carefully age-matched groups, the first with negative TA and the second with relatively high concentrations of TA diagnostic of CLT. The quantitative RIAs employed here for the measurement of TA are considered to be sensitive and specific and therefore it can be assumed that, in most cases, our TA-Neg patients did not have CLT and the TA-Pos patients did indeed have CLT. The emphasis was given to euthyroidism of the patients because hypothyroidism may theoretically be associated with some non-specific destruction of a proportion of $\mathrm{C}$ cells. We found that circulating CT levels were similar between euthyroid goitrous patients with or without CLT (positive TA) and no different from those of normal controls. These data do not support the theory that $\mathrm{CCH}$ occurs with increased frequency in thyroid glands affected by CLT $(8-12)$.

Most patients with the neoplastic form of $\mathrm{CCH}$ (MEN 2 syndrome) and during the earliest subclinical stages of MTC have normal basal serum CT, which, however, invariably rises to abnormally high levels after provocative testing with $\mathrm{Ca}$ or pentagastrin (23). Our finding of similar CT responses after Ca stimulation in both groups indicates that it is unlikely that a mild degree of CCH is present in CLT, because it would be uncovered by this test. The significant positive correlation that we found between basal fasting CT and Ca-stimulated CT demonstrates that a random fasting basal CT level can predict an individual $\mathrm{CT}$ reserve and response to provocative testing, and indicates the diagnostic value of basal CT.

The reported patient with symptomatic $\mathrm{CCH}$ and high serum CT (9), and a second similar patient (8), may

Table 5 Ca-stimulated CT.

\begin{tabular}{lccc}
\hline & Basal CT & Ca-stimulated CT & $\Delta \mathbf{C T}$ \\
\hline TA-Pos $(n=31)$ & 0.09 & 2.06 & 1.61 \\
& $(0.05-0.16)$ & $(1.46-4.12)$ & $(1.11-3.88)$ \\
TA-Neg $(n=27)$ & 0.10 & 2.23 & 1.65 \\
& $(0.05-0.17)$ & $(1.07-4.64)$ & $(0.63-4.33)$
\end{tabular}

Values are expressed in pmol/l and are geometric means with confidence interval in parentheses. 
represent incidental sporadic cases of neoplastic $\mathrm{CCH}$ in CLT. In a series of 24 patients with histologically established CCH, three had high CT levels (10). Guyetant et al. (11) examined retrospectively 112 thyroid specimens with CLT and found $\mathrm{CCH}$ to be present in 20\%; in four cases (about 20\% of those with $\mathrm{CCH}$ ), high serum CT was found before the operation. LiVolsi (22) recently discussed critically the limitations of the morphological methods used for the definition of $\mathrm{CCH}$ in the publications cited above and concluded that the histological findings of $\mathrm{CCH}$ should be correlated with serum CT levels in work of this type.

Horvit \& Gagel (20) commenting on the coexistence of thyroiditis and MTC reported by some authors (19, 24) discussed the possibility of a cause (thyroiditis) and effect (CCH and MTC) relationship. However, it could be argued that rather the reverse relationship may be valid: incidental MTC and $\mathrm{CCH}$ (cause) and effect (reactive thyroiditis). In the cases of incidental MTC, because of the accompanying malignant $\mathrm{CCH}$, the lymphocytic infiltration of the thyroid might be diffuse and not merely focal as in the cases of follicular tumours (6). This possible new relationship can be indirectly supported by our finding of the lack of association between CLT and $\mathrm{CCH}$ in a sufficiently large population of goitrous patients.

Iodine deficiency can induce $\mathrm{CCH}$ and hypercalcitoninemia in rats probably via TSH overstimulation $(25,26)$. Thyrotropin receptors have recently been identified in MTC cells (27). In the present study, basal serum CT levels of the patients with primary hypothyroidism and high TSH were no different from those of the euthyroid patients and normal controls. Moreover there was no correlation between CT and TSH levels. This finding indicates that high TSH probably is not a cause of high serum CT. However, this conclusion should be treated with caution since $\mathrm{Ca}^{2+}$ stimulation tests were not performed on our hypothyroid patients and thus the CT secretion reserve is not known. Possible non-specific destruction of $\mathrm{C}$ cells in hypothyroid glands may obscure a possible stimulatory effect of TSH on C cells. It is noteworthy that endogenous TSH released during TSH-releasing hormone testing in normal subjects and patients with MTC did not induce the secretion of CT (28).

The routine measurement of serum CT in all patients with thyroid nodules as a screening procedure for the early detection of MTC has been recently proposed $(17-19)$. The difficulties in interpreting slightly elevated CT levels in view of the several benign conditions known to be associated with high CT levels have been discussed in a recent editorial (20). Our findings suggest that, if an elevated serum CT (determined by a specific two-site immunoassay) is found in a patient with thyroid nodule and positive TA, it should not be ascribed to the underlying CLT. This patient should be further investigated for some reason other than CLT for the high serum CT.

\section{References}

1 Schwartz KE, Wolfsen AR, Forster B \& Odell WD. Calcitonin in non thyroidal cancer. Journal of Clinical Endocrinology and Metabolism $197949438-444$.

2 Gibson WGH, Peng TC \& Croker BP. Age-associated C-cell hyperplasia in the human thyroid. American Journal of Pathology $1982106388-393$

3 O'toole K, Fenoglio-Preiser C \& Pushparaj N. Endocrine changes associated with the human aging process. III. Effect of age on the number of calcitonin immunoreactive cells in the thyroid gland. Human Pathology 198516 991-1000.

4 LiVolsi VA, Feind CR, LoGerfo P \& Tashijian AH. Demonstration by immunoperoxidase staining of hyperplasia of parafollicular cells in the thyroid gland in hyperparathyroidism. Journal of Clinical Endocrinology and Metabolism 197337 550559.

5 Tomita T \& Millard DM. C-cell hyperplasia in secondary hyperparathyroidism. Histopathology 199221 469-474.

6 Albores-Saavedra J, Montforte H, Nadji M \& Morales AR. C-cell hyperplasia in thyroid tissue adjacent to follicular cell tumors. Human Pathology 198819 795-799.

7 Scopsi L, DiPalma S, Ferrari C, Holst JJ, Rehfeld JF \& Rilke F. C-cell hyperplasia accompanying thyroid disease other than medullary carcinoma: an immunocytochemical study by means of antibodies to calcitonin and somatostatin. Modern Pathology 19914 297-304.

8 Libbey NP, Nowakowski KJ \& Tucci JR. C-cell hyperplasia of the thyroid in a patient with goitrous hypothyroidism and Hashimoto's thyroiditis. American Journal of Surgical Pathology $19891371-77$

9 Biddinger PW, Brennan MF \& Rosen PP. Symptomatic C cell hyperplasia associated with chronic lymphocytic thyroiditis. American Journal of Surgical Pathology 199115 599-604.

10 Barbot N, Guyetant S, Beldent V, Akrass CI, Perdorisot R \& Bigorgne JC. Thyroidite chronique autoimmune et hyperplasie des cellules C. Etude de la secretion de calcitonine chez 24 patients. Annales d' Endocrinologie 199152 109-112.

11 Guyetant S, Wion-Barbot N, Rousselet MC, Franc B, Bigorgne JC \& Saint-Andre JP. C-cell hyperplasia associated with chronic lymphocytic thyroiditis. American Journal of Surgical Pathology $199115514-521$.

12 Perry A, Molberg K \& Albore-Saavedra J. Physiologic versus neoplastic C cell hyperplasia of the thyroid. Cancer $199677750-$ 756.

13 Katoh R. C-cells in Hashimoto's thyroiditis. Ultrastructural and immunohistochemical observations. Acta Pathologica Japonica $1987371611-1620$.

14 Albores-saavedra J. C-cell hyperplasia. American Journal of Surgical Pathology 198913 987-988 (letter).

15 Baschieri L, Castagna M, Fierabracci A, Antonelli A, Del Guerra P \& Squartini F. Distribution of calcitonin- and somatostatincontaining cells in thyroid lymphoma and Hashimoto's thyroiditis. Applied Pathology 19897 99-104.

16 Inoue S, Yokoyama S, Nakayama I \& Noguchi S. An immunohistochemical study of calcitonin-containing cells in benign and malignant thyroid lesions. Acta Pathologica Japonica 199040 187-192.

17 Pacini F, Fontanelli M, Fugazzola I, Elisei R, Romei C, Di-Coscio G et al. Routine measurement of serum calcitonin in nodular thyroid diseases allows the preoperative diagnosis of unsuspected medullary thyroid carcinoma. Journal of Clinical Endocrinology and Metabolism 199478 826-829.

18 Rieu M, Lame MC, Richard A, Lissak B, Sambort B, Vuong-Ngoc P et al. Prevalence of sporadic medullary thyroid carcinoma: the importance of routine measurement of serum calcitonin in the diagnostic evaluation of thyroid nodules. Clinical Endocrinology $199542453-460$.

19 Nicoli P, Wion-Barbot N, Caron P, Henry JF, deMicco C, Saint Andre JP et al. Interest of routine measurement of serum 
calcitonin: study in a large series of thyroidectomized patients. Journal of Clinical Endocrinology and Metabolism 199782 338-341.

20 Horvit PK \& Gagel RF. Editorial: the goitrous patient with an elevated serum calcitonin. What to do? Journal of Clinical Endocrinology and Metabolism 199782 335-337.

21 Motte P, Vauzelle P, Gardet P, Ghillani P, Caillou B, Parmentier C et al. Construction and clinical validation of a sensitive and specific assay for serum mature calcitonin using monoclonal antipeptide antibodies. Clinica Chimica Acta 1988 174 35-54.

22 LiVolsi VA. Editorial: C cell hyperplasia/neoplasia. Journal of Clinical Endocrinology and Metabolism 199782 39-41.

23 deBustros AC \& Baylin SB. Medullary carcinoma of the thyroid. In The Thyroid. A Fundamental And Clinical Text, edn 6, ch 85 , pp 1166-1183. Eds LE Braverman \& RD Utiger. Philadelphia: JB Lippincott Co., 1991.

24 Weiss LM \& Weinberg DS. Medullary carcinoma arising in a thyroid with Hashimoto's disease. American Journal of Clinical Pathology $198380534-538$.

25 Clark OH, Rehfeld SJ, Castner B, Stroop J, Loken HF \& Deftos LJ. Iodine deficiency produces hypercalcemia and hypercalcitoninemia in rats. Surgery $197883626-632$.
26 Peng TC, Cooper CW, Garner SC \& Volpert EM. Hypercalcitonism and $\mathrm{C}$-cell hyperplasia in rats with goiters produced by low iodine diet or propylthiouracil. Journal of Pharmacology and Experimental Therapeutics 1978206 710-717.

27 Elisei R, Pinchera A,Romei C, Gryczynska M, Pohl V, Maenhaut C et al. Expression of thyrotropin receptor (TSH-R), thyroglobulin, thyroperoxidase, and calcitonin messenger ribonucleic acids in thyroid carcinomas: evidence of TSH-R gene transcript in medullary histotype. Journal of Clinical Endocrinology and Metabolism 199478 867-871.

28 Nakamura H, Someda H, Mori T \& Imura H. Thyrotropin releasing hormone induced calcitonin secretion in patients with medullary carcinoma of the thyroid. Clinical Endocrinology 1987 27 69-74.

Received 5 September 1997

Accepted 9 February 1998 